\title{
Quando o Brasil era moderno: o Estado antes da crise do Estado
}

\author{
Adriano Codato $\bullet$ \\ Universidade Federal do Paraná \\ adriano@ufpr.br
}

resumo 0 artigo propõe e desenvolve um esquema analítico baseado no neo-institucionalismo histórico para compreender e explicar a gênese da capacidade estatal a partir de variáveis exclusivamente políticas. Tomando como problema o caso do aumento exponencial do poder estatal durante o regime do Estado Novo no Brasil (1937-1945), procura-se refletir sobre os determinantes empíricos e, derivados deles, os critérios teóricos responsáveis por dar conta de três acontecimentos simultâneos: a centralização decisória no topo do executivo federal; a influência das instituições formais de governo sobre o processo de seleção e recrutamento do pessoal político; e a divisão desigual do poder de decidir entre os diferentes grupos da elite dirigente. Esses três processos estão na base da construção da autoridade do Estado sobre a sociedade (a "soberania") e da nacionalização das estruturas de dominação. Eles funcionaram como precondição para a mudança no modelo de desenvolvimento econômico na primeira metade do século XX. Por contraste, essas variáveis podem servir para pensar o movimento oposto em fins do século $X X$, onde há, como efeito da "crise do Estado nacional-desenvolvimentista", uma erosão da capacidade estatal e a constituição de uma nova dependência econômica.

palavras-chave Estado nacional; instituições políticas; Getúlio Vargas; Estado Novo; neoinstitucionalismo

\section{Introdução: 0 problema}

Em oito de abril de 1939, o ditador do Brasil, Getúlio Vargas, anotou num dos cadernos em que costumava escrever, desde o venturoso 


\section{4}

outubro de 1930, sua rotina administrativa, seus encontros pessoais, alguns lances da política nacional e umas poucas impressões, sobre si e sobre os outros, o seguinte:

“Também não saí [do Palácio Guanabara]. Pela tarde, recebi um jornalista francês, depois o Vilela [Orlando Bandeira Vilela, chefe de gabinete do Ministro da Fazenda, Arthur de Souza Costa], a quem entreguei o decreto que modifica a política cambial, e o Osvaldo [Aranha], com quem tratei da situação internacional e da viagem do general Góis [Monteiro]. Assinei o decreto sobre a administração dos estados e municípios. Recebi também o [Raul] Bopp, com quem estive tratando da escolha dos nomes para o Conselho [Federal] de Comércio Exterior” (Vargas, 1995, II, p. 215; ênfase minha).

Essa entrada, como inúmeras outras desse ano e daquele que o antecedeu, resume e expressa a que ponto havia chegado a centralização decisória sob a ditadura do Estado Novo: o chefe do governo detinha a prerrogativa sobre a política de comunicação com o exterior, a política de comércio exterior e a política de relações exteriores, para ficarmos apenas nos três primeiros itens da agenda do dia. Esse traço característico do regime sugere, entretanto, um processo mais significativo do que a habitual "acumulação de funções" no Presidente (o indivíduo) ou a mera “concentração de poderes" na Presidência (o aparelho).

Tradicionalmente, a literatura assimilou o segundo fato à autonomização do Estado durante o período de transição capitalista aberto em 1930 e o primeiro, ao fenômeno da personalização do poder durante a ditadura de 1937. Em ambos os casos há uma dimensão que não contradiz essas duas (antes, reforça-as), mas que não foi suficientemente enfatizada, nem, o que me parece fundamental, relacionada empiricamente a elas: a capacidade e os meios desse Estado de promover a centralização territorial do poder, para falar como Michael Mann (1992, p. 164). Esse é um aspecto fundamental do processo de State building. Max Weber já havia alegado que "em toda parte, o desenvolvimento do Estado moderno" depende, essencialmente, da "desapropriação dos titulares independentes e 'privados' do poder burocrático que estão ao seu lado, isto é, todos aqueles que possuem meios administrativos, militares, financeiros, tanto quanto bens politicamente utilizáveis de todos os tipos" (WEBER, 1994, p. 315). Não 
por outro motivo, esse foi o alvo principal do primeiro governo Vargas, complementado pelo tal decreto "sobre a administração dos estados e municípios" (decreto-lei 1 202/39).

O propósito deste artigo é, resumidamente, expor e explicar um esquema indutivo que permita compreender a gênese e o desenvolvimento da capacidade estatal a partir de variáveis exclusivamente políticas. Tomando como problema concreto o caso do aumento exponencial do poder estatal durante o regime do Estado Novo no Brasil (19371945), procuro refletir sobre os determinantes empíricos e, derivados deles, os critérios teóricos responsáveis por dar conta analiticamente de três acontecimentos simultâneos: $i$ ) a centralização decisória no topo do Executivo federal, em detrimento dos estados mais importantes (São Paulo, em primeiro lugar); ii) a influência das instituições formais de governo (conselhos, comissões, departamentos) sobre o processo de seleção e recrutamento do pessoal político, em substituição aos mecanismos tipicamente liberais (partidos, eleições) vigentes até então; e iii) a divisão desigual do poder de decidir entre os diferentes grupos da elite, graças à marginalização das "oligarquias tradicionais" e seu correlato: a promoção ao primeiro plano da cena política de uma elite estatal com uma perspectiva modernizante.

Esses três processos históricos - impossíveis, todavia, de serem detalhados aqui - estão na base da construção da autoridade do Estado sobre a sociedade (a "soberania") e da nacionalização das antigas estruturas de dominação, o que levou, por sua vez, a uma redefinição das condições de exercício dos poderes privados (o mandonismo, o coronelismo e o clientelismo). Conforme esse raciocínio, nossa hipótese ou mais propriamente, o ponto de partida desse raciocínio - é que o movimento de construção de um Estado nacional, autônomo e soberano funcionou como precondição, e não como conseqüência, para a mudança do modelo de desenvolvimento econômico na primeira metade do século XX. Por contraste, essas variáveis políticas todas podem servir para pensar, num segundo momento, o movimento oposto em fins do século XX, onde há, como efeito da "crise do Estado nacional-desenvolvimentista" e da ascensão das autoridades supranacionais, uma erosão da capacidade estatal e a constituição de uma nova dependência econômica. 
O peculiar desse processo de State building é que tanto o meio como o modo de realização dessas tarefas de 1930 em diante têm como fundamento o autoritarismo. Esse ponto merece um breve esclarecimento.

"Autoritarismo", tal como utilizado aqui, é uma expressão concisa cuja ambição é resumir e explicar o segredo desse modo de dominação, e não simplesmente designar o nome do regime político. É essa fórmula, cuja melhor expressão, mas não a única, é a concentração do poder executivo no Executivo e a comemoração da autoridade do Estado sobre a sociedade, que garante as relações de negociação e subordinação no universo da elite (cf. Martins, 1976, p. 24) e que estrutura as posições objetivas (quem manda/quem obedece) e as disposições subjetivas (o que se pensa/como se pensa para justificar, justamente, o mando e a obediência) nesse universo. Por isso, o que deve contar é menos o grau ou a extensão em que o autoritarismo é exercido pelos agentes e pelas agências burocráticas do Estado, e mais a configuração institucional - os aparelhos e a hierarquia entre os aparelhos - que permite que ele seja exercido até mesmo contra a antiga elite dirigente e graças ao consentimento ativo desta.

Separei a exposição em quatro partes. Na primeira, recordo um momento preciso da evolução política brasileira a partir dos debates em torno da necessidade de uma nova ordem administrativa. Ressalto o aspecto que me parece central nas postulações por uma nova relação entre Estado e Nação: o autoritarismo não como ideologia justificadora do poder dos poderosos, mas como fórmula institucional, como instrumento de construção nacional.

$\mathrm{Na}$ segunda parte procuro explicar em termos sumários a noção de "capacidade estatal", fórmula que inclui, mas ultrapassa, a organização da estrutura política do Estado Novo e seu sucedâneo, "o poder presidencial", isto é, a centralização do poder de decidir no vértice do sistema estatal.

$\mathrm{Na}$ terceira parte do ensaio apresento alguns pressupostos sobre o papel das instituições na vida política e na explicação da vida política. Mais do que definir uma filiação teórica ou um quadro conceitual ideal, explico as utilidades práticas de uma abordagem - um método de análise, por assim dizer - mais de acordo com o assunto perseguido aqui: o trabalho histórico de produção do poder, de institucionalização do poder e de distribuição do poder político. 
$\mathrm{Na}$ última parte, retomo alguns traços típicos do Estado brasileiro num período determinado do seu desenvolvimento, procurando relacioná-los à sua capacidade política como aparelho burocrático "sobre pessoas e territórios”, para falar como Weber, à sua disposição para organizar e definir as relações sociais e as relações econômicas, e à sua independência diante da antiga classe dominante (idéia que é diferente da sua "autonomia relativa").

\section{0 Estado brasileiro: uma nuvem de palavras}

Apesar do estilo econômico de Vargas, a eleição dos nomes para o Conselho Federal de Comércio Exterior, referida de passagem na passagem citada atrás, não era um expediente burocrático a mais da ditadura "getulista". Da mesma maneira, o Código dos Interventores, conforme ficou conhecido o decreto-lei de 1939 que deveria regulamentar a administração dos estados e dos municípios, não deve ser tomado apenas como outra modificação legislativa tentada pelo regime para aperfeiçoar a Constituição de 1937 ou corrigir os possíveis desajustes no desenho institucional. Tanto uma decisão como outra exprimem a diversidade - e a complexidade das estruturas de comando do governo sobre o País (social no primeiro caso, regional no segundo) e a necessidade de mecanismos políticos distintos a serviço da centralização, a compulsão da época.

Muito freqüentemente, essas novas modalidades de articulação entre o Estado e a sociedade vinham ou embrulhadas na ideologia da racionalização administrativa (Vianna, 1974, p. 135-147), ou recobertas pela eloqüência do nacionalismo confiante em sua missão salvacionista e modernizante (como em Azevedo Amaral, 1938). O caso da centralização do poder regional, por exemplo, revela, sob o palavrório da unidade nacional, uma ambição tripla. Tratava-se de reordenar o território, dando ao federalismo um novo significado e uma nova utilidade. Seria preciso igualmente suplantar as identidades particulares (língua, símbolos, etnias, classes etc.), abolindo tudo aquilo que não se referisse ao "Brasil". Enfim, era mais do que urgente unificar politicamente o País sob a direção e o comando de um chefe único, o Presidente ditatorial. Implicitamente, e esse é o ponto menos debatido dessa estratégia, havia a pretensão de 


\section{8}

refazer a hierarquia política entre os grupos de elite, enquadrando os “imperialismos estaduais", conforme o peculiar vocabulário dos ideólogos do regime estadonovista.

Cogitações sobre o problema do regionalismo, as qualidades óbvias do Estado unitário e as vantagens de um governo tipicamente nacional eram temas presentes em todos os escritos de todos os explicadores do Estado Novo. Monte Arrais, num dos primeiros estudos sobre "o verdadeiro sentido das novas instituições", incumbiu-se não apenas de interpretar as diretrizes do regime de 1937, mas de louvar seus "intuitos de nacionalização e unificação", propósitos "tão profundamente almejados pelas massas", segundo ele mesmo. Em seu comentário às intenções, aos princípios e à oportunidade do "Monumento Político" que nos regia (a Constituição do 10 de Novembro), observou que a "estabilidade institucional" de um país sob o regime federativo, como no caso do Brasil, dependia de três fatores: da igualdade jurídica e política dos estados frente à União (em bom português: da subordinação de São Paulo ou de qualquer outro "império regional", como Minas Gerais ou o Rio Grande, ao Executivo federal); da firmeza com que a União desse vida a tal "preceito" (o que de resto explicava e justificava o autoritarismo político); e da forma pela qual cada unidade política ficaria restrita, pela União, à esfera pré-determinada de seus "interesses particulares", sem intrometer-se no governo do Brasil (Monte Arrais, 1938, p. 8, 22, 8 e 56-57, respectivamente).

A capacidade política da "União" - os aparelhos e as instituições nacionais do Estado nacional - era o assunto incontornável da década de trinta.

Francisco Campos, por exemplo, ressaltou, com o entusiasmo habitual, que cinqüenta anos de governo de uma Constituição liberal, cinqüenta anos de vigência de um falso sistema representativo, cinqüenta anos cultuando o mito do sufrágio universal e outras miragens parecidas, produziram um Estado que não passava de uma "nuvem de palavras". As instituições políticas brasileiras, segundo ele, eram inadequadas "até ao próprio espaço" territorial sobre o qual se deveria exercer "a autoridade do governo". Com o Estado Novo, essa fantasmagoria deixaria de ser uma abstração para se tornar um fato político, e a política dos estados, graças ao Estado ditatorial, seria enfim substituída pela "política da Nação”. Mas, note: "Nação não é apenas número e espaço: é preciso orga- 
nizar o número e articular o espaço, pôr forma e dar à Nação o sentimento de que ela constituiu um só corpo e uma só vontade. Fora dos quadros estabelecidos pela técnica do Estado Novo não há solução para o problema social e político do Brasil" (Campos, 1938, p. 11-12; grifos meus). Ou seja: fora do autoritarismo é impossível organizar o poder de Estado em bases de fato nacionais. É ele que viabiliza, nesse contexto, a capacidade estatal.

Nesse sentido, o autoritarismo foi, além de uma ideologia, um método, um modo de proceder, que exigiu e impôs um dado arranjo institucional. Como nesse período as formas de governo eram efetivamente uma questão de escolha, para retomar a célebre fórmula de Stuart Mill, talvez fosse interessante, até para perceber a relação concreta entre política e território, ou mais propriamente, entre a organização política e o exercício do poder sobre um determinado território (conforme a problemática weberiana), olhar para a materialidade do Estado. Um dos passos decisivos para "articular o espaço" nacional e impor ao País "uma só vontade", a do Presidente da República, convertido pela ideologia teórica dos teóricos do autoritarismo em "Chefe da Nação", foi justamente edificar um mecanismo político-administrativo de supervisão sobre as classes dirigentes estaduais. É através dele que se pode estipular a capacidade desse Estado instituir uma nova divisão do poder entre os diferentes grupos da elite e agir de forma autônoma.

\section{A construção do poder de Estado}

Um dos fatos mais intrigantes desse período é a necessidade da "ditadura getulista" dar a si um aparato jurídico-constitucional, como se comprova tanto pela extensa atividade legiferante até 1945, como pela originalidade de um golpe de Estado cujo primeiro procedimento não foi a repressão policial, mas, sintomaticamente, a imposição de uma Carta Constitucional. Por isso mesmo o "Estado nacional" não deve ser estudado exclusivamente como uma ideologia dos círculos dirigentes, secundada pela teoria dos ideólogos de Estado, conforme o ponto de vista de Elisa Reis (1988), mas como um aparelho, ao mesmo tempo institucional e legal.

Esse tópico compreende, a meu ver, os problemas tradicionais da limitação das prerrogativas regionais, da centralização do poder decisório no 
nível nacional e da autonomia do aparelho do Estado brasileiro, o cardápio obrigatório do Estado Novo, mas não apenas. Entender como estava organizado politicamente o regime ditatorial e como funcionava burocraticamente o governo nacional, a questão histórica desse período, implica em olhar com muito mais atenção para a materialidade institucional do Estado autoritário. Essa mudança de perspectiva permite considerar a questão teórica que constitui o núcleo desse assunto: a construção do poder de Estado sobre a Nação.

É um erro assimilar o antiliberalismo que animou a ideologia oficial em meados do século XX no Brasil e que, na prática, implicou na abolição da representação política pelas vias partidárias e parlamentares usuais, a uma disposição antiinstitucional.

A crítica autoritária da política liberal tradicional e das suas práticas oligárquicas, para ser ideologicamente conseqüente e politicamente eficaz, não poderia se limitar a cancelar as licenças de funcionamento das associações civis, destruir os partidos, trancar os parlamentos e perseguir os políticos profissionais que não se alinharam voluntariamente com o novo regime. Ela teria de criar instituições políticas adequadas ao espírito do tempo. Isso por uma razão trivial: a decantada capacidade de manipulação das massas e conciliação das elites, traço característico da liderança "populista" de Vargas, não seria garantida, no caso das primeiras, graças apenas ao carisma pessoal e, no caso das segundas, graças somente às lealdades pessoais devidas (por exemplo) pelos Interventores ao Presidente que os havia nomeado. Assim, da mesma maneira que o caráter "personalista" do novo regime, que transformou Getúlio no centro político do Estado Novo e projetou sua imagem como árbitro da Nação e salvador do Brasil, seria o produto de um conjunto de aparelhos, instituições e práticas específicas ${ }^{1}$, as circunstâncias do Estado Novo ressaltam a necessidade política de organizar um sistema estatal centralizado, hierarquizado e burocratizado, e não simplesmente o regime arbitrário do caudilho e do Ditador, como os paulistas estavam acostumados a referir-se, quando lhes convinha, ao Chefe político nacional (cf. Oliveira, 2002, passim). Quase sempre há uma relação empírica entre o número de instituições e o grau da autonomia, assim como entre o processo de institucionalização do poder de Estado e a autonomização política dos seus agentes. 
Esses problemas, em particular, estiveram freqüentemente encobertos por duas imagens simétricas e opostas, associadas ambas ao "regime varguista". Ora o sistema de dominação foi percebido como um sistema pouco ou nada institucionalizado, garantido apenas pelo carisma do caudilho encarnado na pessoa do governante (o "governo populista"); ora como um dispositivo institucionalizado em demasia (o "Estado burocrático", no sentido positivo da expressão), característica essa que resultaria do propósito anunciado e do sucesso obtido graças à modernização e racionalização da máquina governamental no pós-1930.

Minha suposição é que a solução da delicada questão da centralização territorial do poder - que implicava numa nova divisão social entre os grupos oligárquicos, numa nova disposição política das diversas facções de elite no espaço político e a nova distribuição burocrática do poder político entre as diferentes linhagens da classe política - resultou da nova ordem e da nova hierarquia estipulada pelos círculos dirigentes do regime entre os diferentes níveis do sistema estatal. Assim, a estrutura da elite dirigente foi, nesse caso, uma função da estrutura do Estado.

Essa forma de ver as atribuições das instituições políticas está associada à noção de capacidade estatal que mencionei mais acima. A expressão, proposta por Theda Skocpol (1985), reúne e designa certas idéias particularmente úteis para o estudo da constituição do poder de Estado no Brasil.

Em primeiro lugar, essa noção teórica sugere que é preciso, contra as explicações societalistas, conceber o Estado como um ator ${ }^{2}$, isto é, assumir que parte dos agentes estatais (aqueles com poder) são capazes de formular e perseguir intenções e objetivos definidos a partir de suas próprias prioridades, e não como meras respostas a demandas sociais. Claro está que a capacidade de implementar efetivamente essas preferências nunca é absoluta, mas está condicionada pela relação concreta entre os agentes estatais, e seus recursos, e os agentes não-estatais, e seus interesses.

A idéia de "capacidade estatal" sugere também que é preciso imaginar o Estado não só como um ator, mas como um fator determinante: as configurações organizacionais do Estado, ou mais simplesmente, suas estruturas institucionais influenciam de forma decisiva as idéias, os negócios e as competências políticas dos diferentes grupos sociais. O Estado, portanto, não é (ou não deve ser visto como) uma arena neutra onde interesses se exprimem e se enfrentam. Nunca é demais recordar também 
que as ações do Estado, seja como ator, seja como fator são sempre historicamente determinadas, ou melhor, são "sensíveis às variações estruturais e às mudanças conjunturais que ocorrem dentro de sistemas políticos determinados" (Skocpol, 1985, p. 14).

Claro está que as ações da elite estatal e, principalmente, a extensão do seu poder ou a aptidão para bolar e pôr em prática seus propósitos ficam igualmente condicionadas à "extensão" e às variações internas da organização do aparelho estatal - e não apenas às regras, aos recursos, aos expedientes práticos derivados do ordenamento jurídico; ou aos valores implícitos e às idéias explícitas, isto é, aquelas ideologias que confirmam e propagam sua força social. Erik Nordlinger observa bem a propósito que os interesses e

"as preferências [dos agentes estatais] são moldadas por necessidades organizacionais e rivalidades sobre a política de governo a ser seguida, sobre o orçamento, sobre [o grau] de autonomia interna e o prestígio [que desfrutam]. [...] Os agentes estatais preferem políticas que ajudem a estruturar e fortalecer sua autonomia". Assim, prossegue ele, "os recursos oficiais (e mesmo algumas habilidades) são institucionalmente derivados [da organização estatal] e seu uso efetivo e seu impacto, mediados por normas institucionais e regras de decisão" (1988, p. 882).

Tendo esses princípios em mente, vejamos o porquê da prioridade conferida aqui às instituições e à configuração institucional do Estado nesse tipo de explicação.

\section{A política das instituições políticas}

III.1 O que são instituições?

A análise da vida política está ligada à compreensão de vários fatores diferentes: à influência das crenças, das idéias e dos valores socialmente compartilhados sobre comportamentos de indivíduos e grupos (como no caso dos estudos que destacam o papel da “cultura política”); à compreensão da eficiência dos cálculos estratégicos dos atores e das oportunidades de maximização das preferências individuais a partir de determinadas regras ou contextos institucionais (como na "teoria da escolha 
racional"); ou ainda à identificação dos constrangimentos sociais mais amplos sobre os agentes sociais, resultado da estrutura econômica e da estrutura de classe dela derivada (conforme a visão, muito simplificada, do que seria “o marxismo").

Além dessas chaves de interpretação, a análise da vida política está condicionada à percepção da ascendência das instituições formais, dos marcos legais, das rotinas organizacionais, das estruturas governamentais e de seu papel ativo sobre os resultados políticos (political outcomes). O pressuposto básico dessa visão institucionalista é um tanto simples (sem deixar de ser verdadeiro): "a maioria das ações políticas de certa importância ocorre no interior de instituições [políticas]; por isso é decisivo compreender como agem esses aparatos e como influem no comportamento dos indivíduos que atuam em seu interior" (Peters, 2003, p. 219-220).

De forma resumida, o argumento central do novo institucionalismo em Ciência Política pode ser desdobrado em três postulados: $i$ instituições - e não indivíduos ou classes - são o elemento central da vida política; ii) indivíduos são 'atores' importantes, mas é mais proveitoso compreender quais são os marcos institucionais dentro dos quais eles agem, ao invés de observar o próprios indivíduos, suas motivações, preferências e escolhas; portanto, iii) não apenas instituições "contam” na explicação, mas são a explicação para a maior parte das ocorrências da vida política.

Todavia, a própria definição do que são "instituições” é polêmica. Há três versões diferentes que correspondem também a três maneiras diferentes de pensar a influência (ou a ação determinante) das instituições na explicação da vida social.

Instituições podem ser, por exemplo, normas e valores, incluindo sistemas simbólicos, esquemas cognitivos, modelos morais etc., que não só estipulam o funcionamento de organizações, mas determinam o comportamento individual através de uma série de categorias de percepção que guiam a prática social dos agentes, determinam inteiramente suas preferências, interesses, objetivos, como é o caso da definição do neo-institucionalismo "clássico" (March e Olsen, 1984; e March e Olsen, 1989, p. 39-52) ${ }^{3}$. Instituições podem ser, por outro lado, sistemas de regras e incentivos (procedimentos) a partir dos quais indivíduos, sempre com base em cálculos estratégicos a respeito de suas conveniências, definem preferências e tentam maximizar seus interesses, conforme quer o institucionalis- 


\section{4}

mo da escolha racional (Shepsle, 1989) ${ }^{4}$. Por fim, instituições podem designar simplesmente instituições formais (ou "organizações"), como, por exemplo, as instituições políticas, incluindo aí procedimentos burocráticos, estruturas governamentais, aparelhos estatais, normas constitucionais (Ikenberry, 1988). Uma vez constituídas historicamente, elas têm impacto decisivo sobre o comportamento dos agentes inseridos no sistema político (legisladores, eleitorado, grupos de interesse e de pressão etc.), determinando resultados políticos (Krasner, 1984). Essa é a definição proposta pelo neo-institucionalismo histórico. É nesse sentido que "instituição" é utilizada neste ensaio.

Parte-se aqui da suspeita que instituições - regras formais, normas tácitas e estruturas políticas, principalmente essas últimas - "importam" numa medida, contudo, a ser estipulada por meio da pesquisa histórica.

Fatores institucionais são particularmente importantes já que definem ou modelam as preferências, os objetivos e os interesses dos agentes sociais (e não apenas "estratégias" de ação). Eles distribuem desigualmente o poder entre cada um deles (medido por suas influências respectivas sobre um determinado processo decisório, por exemplo), estabelecendo, a partir daí, uma determinada hierarquia entre os agentes sociais (cf. Hall, 1986, p. 19). Em resumo, instituições estruturam a (ação e a relação) política. Não são, nesse sentido, apenas um “contexto”, um lugar ou uma paisagem. Ao contrário: são as próprias instituições que devem ser inseridas no contexto histórico-social (cf. Steinmo, Thelen e Longstreth, 1992).

\section{III. $2 \mathrm{O}$ institucionalismo histórico}

Em grande medida, o institucionalismo histórico continua e aprofunda o projeto proposto por Theda Skocpol de trazer "o Estado" de volta à cena teórica e resgatar sua função explicativa. Como ela enfatizou, essa postura teórica e metodológica "requer que se veja o Estado como algo muito maior que uma mera arena onde os grupos sociais apresentam suas demandas e travam combates ou celebram compromissos políticos". Exagerando um pouco o argumento, "Só na medida em que exista a formulação de objetivos independentes em relação a grupos sociais poderosos ou a constrangimentos socioeconômicos faz sentido falar dos Estados como atores relevantes" (Skocpol, 1985, p. 8 e 9; grifo meu). 
A abordagem dos institucionalistas históricos (e essa é sua maior vantagem) é bem mais politizada do que sua versão sociológica ou a versão baseada na teoria da escolha racional. Esquematicamente, poderíamos dizer que para o institucionalismo da escolha racional instituições são a regra do jogo social e seu interesse principal é saber qual é o jogo e como ele é jogado. Já para o institucionalismo histórico instituições são os constrangimentos institucionais que atuam ao longo do tempo sobre ações e escolhas políticas. Suas perguntas fundamentais são: dado um determinado arranjo político, quem ganha, quem perde e por quê? Faz parte dessa abordagem, e da agenda de pesquisa dela derivada, investigar mais a fundo a distribuição assimétrica dos recursos políticos (isto é, as condições que precedem o jogo propriamente dito) e meditar sobre relações de poder conflituosas, vendo as próprias instituições não como elementos neutros onde o jogo político é jogado, mas como "produtos derivados da luta entre atores desiguais" (Steinmo, 2001, p. 365).

Ainda conforme a versão mais exigente dessa corrente, "instituições" não são apenas os elementos formais do Estado, embora também os incluam, evidentemente. A expressão designa, na realidade, o desenho ou a configuração institucional que define e orienta as relações políticas entre os aparelhos, seus ocupantes e o mundo político.

Análises e interpretações devem, portanto, focalizar não instituições específicas, mas processos causais que operam num nível interinstitucional. Configurações institucionais (mais do que instituições isoladas) podem explicar tanto os próprios arranjos institucionais, quanto os produtos políticos a partir dele. Daí a necessidade de pensar o todo para decifrar a parte. Trata-se de explicitar como um conjunto de instituições inter-relacionadas molda processos, acontecimentos, decisões etc. É duvidoso que a inspeção de uma instituição isolada possa determinar efeitos institucionais. A interação entre instituições é que produz conseqüências efetivas.

Em nosso caso, o estudo do "Estado brasileiro" (o objeto empírico) não pode estar desligado da teia institucional da qual ele é parte (o sistema político) e sobre o qual ele age (o universo das elites). Como Paul Pierson e Theda Skocpol observaram, um set, um grupo de instituições tende em geral a se complementar e a se reforçar mutuamente (Pierson e Skocpol, 2002, p. 693-721), sugestão que abre espaço para pensar os Departamentos Administrativos como fazendo parte de um mesmo 
sistema político e institucional que as Interventorias, os Departamentos das Municipalidades, o Ministério da Justiça, a Presidência da República etc., dependendo das e influindo nas suas relações recíprocas.

\section{III.3 Tempo, lugar e contexto}

No entanto, nem os mesmos interesses sociais, nem as mesmas instituições políticas produzem, em todo o lugar, os mesmos resultados. Essas forças/aparelhos são modificadas pelas propriedades particulares de cada contexto político, sendo essas propriedades herdadas da história e da geografia. Logo, as idéias de tempo e lugar são aqui decisivas.

Do mesmo modo, a compreensão do processo de interação entre várias instituições só faz sentido se referido ao contexto social mais amplo, cuja influência deve ser avaliada, contudo, a partir de uma perspectiva temporal. Isso significa, em resumo, que a trajetória histórica dessas propriedades determina a configuração política e a distribuição de poder na situação presente.

Parece que há, hoje, um movimento de revalorização da dimensão histórica dos processos políticos pela Ciência Política. Sem que os grandes modelos explicativos tenham sido abandonados, ou mesmo relegados a um segundo plano, os estudos da área passaram a valorizar, ao lado do desenho institucional e suas conseqüências sobre os "atores" e suas "estratégias", o desenvolvimento institucional com base em pesquisas histórico-comparativas. Mesmo sem assumir o desafio proposto por Charles Tilly há mais de duas décadas, voltar a estudar "big structures, large processes, huge comparisons", mas focalizando apenas conjunturas críticas (momentos de transição ou de transformação de regimes políticos e modelos de acumulação, por exemplo), a abordagem histórica permite detectar ou sugerir interações entre seqüências causais distintas que podem confluir num momento determinado para explicar eventos determinados. O mapeamento de processos histórico-sociais (process tracing) é um método de enfoque especialmente útil para questionar a identificação indevida entre correlação estatística e causalidade.

Modelos muito formalizados, postulados teóricos universais e (eu acrescentaria) tipologias abstratas, acreditam os institucionalistas históricos, podem perder relações causais mais complexas, ignorar hipóteses 
válidas ou desconsiderar importantes resultados políticos de processos sociais. Daí sua insistência em olhar não para o passado, mas, como advertiram Pierson e Skocpol, para "processos através do tempo" (processes over time). Segundo essa compreensão do processo político, tudo depende dos "contextos": a atuação e a importância das instituições, sua influência sobre as preferências e as competências dos agentes políticos e as relações de poder entre esses últimos e "a sociedade" estão sujeitas, num dado contexto histórico, à combinação específica de muitas variáveis diferentes e de pesos muito desiguais entre si (Immergut, 1998, p. 19-23) 5 .

Há três tópicos presentes na agenda de pesquisa dos institucionalistas históricos e, em rigor, na agenda de pesquisa de qualquer estudioso do Estado, do seu aparelho e do seu poder: a questão da gênese institucional, a questão do desenho institucional e a questão dos efeitos institucionais da organização do Estado brasileiro pós-oligárquico. Esse cardápio permite reconsiderar algumas questões tradicionais e, sobretudo, algumas respostas tradicionais a elas.

\section{0 Estado ditatorial}

A nacionalização das estruturas de poder, ao mesmo tempo propósito e produto da centralização política no pós-1930, foi em geral interpretada pela historiografia e pela sociologia brasileiras de duas maneiras: em termos teóricos, como condição de possibilidade de autonomização do Estado diante da sociedade; em termos históricos, como a concretização da vontade de um Presidente imperial.

Em ambos os registros, o "caudilhismo", ou sua versão modernizada, o "populismo autoritário" são confissões de um modo de desenvolvimento político em que o programa de superação dos poderes privados (os "imperialismos estaduais") ou carece de mediações institucionais, tal como no fenômeno da ligação direta entre o Presidente e as elites políticas; ou excede em mediações institucionais, como atestam todos os relatos sobre o crescimento e a burocratização do Executivo federal nesse período (cf. Cunha, 1963). Em quaisquer dessas explicações o Estado Novo - que é o paroxismo desse negócio todo - fica assimilado apenas a uma experiência relativamente bem-sucedida de “'desapropriação' dos 


\section{8}

instrumentos locais e regionais de poder estruturados sob o Estado oligárquico" (Draibe, 1985, p. 62).

Talvez não tenha sido enfatizado suficientemente que a transferência de poder de um nível a outro do sistema político brasileiro - do regional para o nacional - não foi apenas uma questão de cessão de direitos ou alienação de "funções" dos estados ao Estado. Esse processo não poderia prescindir de arranjos formais que garantissem, ao lado da unificação do mercado econômico, a unificação do "mercado político”. Explico.

Assim como o deslocamento do eixo dinâmico da acumulação (da economia agromercantil para a industrial), ele mesmo o resultado prático da ação efetiva de órgãos de planejamento, agências decisórias, burocracias públicas e da atuação de uma elite estatal planejadora - enfim, da "intervenção" do Estado - não resultou automaticamente da "lógica do sistema capitalista" (seja nacional, seja internacional), a mudança de escala em que o poder de classe e o poder de Estado passaram a ser exercidos não derivou de adaptações paulatinas e sucessivas da estrutura de poder. Tanto é assim que o problema da hierarquização e da integração entre os subsistemas econômicos regionais, o problema do controle político sobre as elites políticas estaduais e a questão da dominação ideológica sobre a sociedade só foram suficientemente resolvidos graças à ditadura do Estado Novo (Martins, 1983, p. 685). Eles exigiram portanto uma mudança de regime, uma transformação político-institucional, enfim.

IV.1 Gênese, desenho e efeitos institucionais

\section{IV.1.1 Gênese institucional}

A gênese institucional do Estado ditatorial e sua compreensão são estratégicas para entender o programa de construção da capacidade estatal, afastando assim as concepções que, com base numa "história administrativa" que faz abstração da sociedade e de seus conflitos, tende a ver a criação e a imposição de novos parâmetros burocráticos apenas como o efeito de manobras adaptativas ao novo "ambiente político"; ou como correções marginais das disfunções do desenho institucional original; ou ainda, tende a tomar tais parâmetros por simples imitação de modelos externos, ou por decorrências automáticas de reformulações das visões correntes sobre a melhor forma de governar, e assim por diante. 
Pierre Bourdieu lembrou que, em se tratando do Estado e dos processos de instituição do poder do Estado, não há maneira "mais poderosa” de romper com a visão naturalizada do desenvolvimento natural das instituições políticas e das práticas administrativas e jurídicas estabelecidas desde sempre "do que a reconstrução da gênese: ao fazer com que ressurjam os conflitos e os confrontos dos primeiros momentos e, concomitantemente, os possíveis excluídos", essa perspectiva sócio-genética "reatualiza a possibilidade de que houvesse sido [...] de outro modo [...] e recoloca em questão" aquele modo de organização que historicamente "se concretizou entre todos os outros" (Bourdieu, 1996, p. 98).

São portanto conjunturas críticas de escolhas institucionais historicamente determinadas por agentes históricos determinados que permitem apreender as interações políticas entre elites e instituições. Thelen e Steinmo sugeriram, na mesma linha de argumentação, que "cientistas políticos deveriam estar particularmente interessados em momentos de opção e de mudança institucional". Para todos os efeitos, "a evolução política é um atalho ou um processo ramificado e o estudo dos pontos de partida de padrões estabelecidos [...] são essenciais para uma compreensão mais ampla da história política" (Thelen e Steinmo, 1992, p. 27).

IV.1.2 Desenho institucional

O desenho do sistema institucional dos aparelhos do Estado, por sua vez, e a imposição de uma dada configuração (a morfologia de suas partes e a fisiologia desse organismo) respondem a três ordens de elementos diferentes e se a abordagem é indutiva, convém não estipular de antemão a prioridade de uma explicação sobre outra ou uma hierarquia rígida entre os fatores considerados.

O arranjo institucional sempre poderá ser influenciado pela dinâmica histórica concreta, determinado por imperativos estruturais do sistema social e/ou eleito intencionalmente a partir de disputas (políticas ou "ideológicas") em torno do melhor formato político para garantir, segundo seus inventores, eficiência à administração, legitimidade ao poder, estabilidade ao governo, desenvolvimento ao país, unidade à nação etc., ou muito simplesmente, para garantir o próprio poder de mandar. Contingências históricas (a "Política"), exigências sistêmicas (a "Economia”) e preferências doutrinárias dos agentes (a "Ideologia”) são assim responsáveis, em 
graus diferentes e segundo os contextos, pela forma do Estado e pelo modo de exercício do poder de Estado.

No primeiro caso, mudanças no contexto político ou econômico, mais do que uma abstrata aprendizagem do sistema com seus próprios erros e acertos, restringem e definem a quantidade de aparelhos, os tipos de aparelhos, a disposição dos aparelhos e suas funções respectivas. No segundo caso, a "tecnologia organizativa" do Estado, para falar como Göran Therborn (1978), ou os "procedimentos formais", a expressão que Claus Offe (1975) usa para designar os modos de operação do Estado, são determinados, em maior ou menor grau, de forma direta ou indireta, pela dinâmica social e pelas funções específicas que esse Estado tem de cumprir numa sociedade de classes. No último caso dessa lista, o suposto é que os desenhadores de instituições têm grande liberdade para selecionar, por exemplo, formas de governo ou tipos de regimes políticos de acordo com suas "preferências", como a vastíssima literatura sobre presidencialismo versus parlamentarismo, por exemplo, sugere (cf., por exemplo, Sartori, 1994).

O comunicado radiofônico que anunciou o golpe de 10 de Novembro e a ênfase do seu redator na inconveniência da "manutenção desse aparelho de Estado inadequado e dispendioso" - e na necessidade correspondente de se criar um conjunto de "órgãos apropriados através dos quais [a Nação] pudesse exprimir os pronunciamentos da sua inteligência e os decretos da sua vontade", alterando assim, completamente, a estrutura herdada - ilustra bem como se assume uma determinada forma de resolver conflitos, sem deixar de explicar porque se pôde chegar a uma situação em que "as exigências do momento histórico e as solicitações do interesse coletivo" reclamavam "a adoção de medidas que [afetassem] os pressupostos e convenções do regime, os próprios quadros institucionais, os processos e métodos de governo", isto é: tudo (Vargas, 1938, p. 25, 32 e 19 , respectivamente).

Nas três versões do argumento sobre as razões do ordenamento das estruturas governamentais (conjunturas políticas, determinações econômicas e predileções doutrinárias) há sugestões úteis para pensar o objeto empírico deste ensaio: o processo de construção do Estado nacional no Brasil depois de 1930. Como enfatizei no final da seção anterior, as condições históricas que presidiram a formação, a transformação 
e a imposição de uma determinada configuração institucional dizem respeito, de maneira direta, tanto ao contexto, ou à conjuntura, quanto, indiretamente, ao ambiente, ou à estrutura que orientou a ascensão e a decadência de determinados modelos de acumulação.

Assim, conseqüências não previstas de conflitos políticos, tanto quanto o "sistema capitalista", agem para definir uma dada configuração institucional. O que significa, enfim, que mudanças expressivas no contexto político, conflitos entre forças sociais diferentes, redefinição de objetivos e estratégias de agentes e a necessidade de impor uma nova geografia aos grupos da oligarquia forçaram um novo marco institucional cujo desenho teve de ser funcional (ou ao menos não pode ser disfuncional) para "a economia", isto é, para a (re)definição da posição das classes e frações na estrutura social, ao mesmo tempo em que teve de ser instrumental para as finalidades políticas a que se propunha: transferir poder político e influência política de uma facção da elite a outra. Aqui as escolhas voluntárias dos agentes estatais - cujo grau de liberdade varia conforme as condições políticas, o poder efetivo que reúnem e o prestígio "intelectual" que suas soluções desfrutam - não podem ser desprezadas em nome da lógica abstrata do "sistema" (as exigências do modo de produção capitalista etc.).

Essas escolhas, cuja liberdade está mais sugerida pela palavra do que pela coisa em si, estão, por sua vez, condicionadas pelas ideologias teóricas (no caso, recobertas por suas respectivas "doutrinas constitucionais": antiliberalismo, autoritarismo, corporativismo etc.) e pelas estratégias práticas que visam dar a si ou ao seu grupo uma posição vantajosa no jogo político ${ }^{6}$. Opções institucionais são, assim, tanto o efeito da ideologia política predominante, já que seria insensato imaginar que a sentença de Francisco Campos - "para as decisões políticas uma sala de parlamento tem hoje a mesma importância que uma sala de museu" (Campos, 1940, p. 28) - pudesse ser pronunciada e acatada fora do período de ascensão dos chamados totalitarismos; quanto o resultado planejado da elite política dominante para garantir aos seus protagonistas, ou às facções que eles representam, poder, mesmo que essa intenção apareça como a realização metafísica de uma lei da natureza: "O Estado marcha para a legislação pelo Executivo como o Sol para a constelação de Hércules" (Campos, 1940, p. 101). 
IV.1.2 Efeitos institucionais

O problema dos efeitos institucionais - entendidos aqui como os impactos concretos que as interações entre as instituições políticas provocam nos processos políticos, incluindo toda sorte de resultados: a modelagem de interesses, a interação com valores, a definição comportamentos, a hierarquização entre os centros de poder burocráticos, a disposição dos diferentes grupos por eles e a própria transformação do perfil dos indivíduos aí engajados - é diferente desses dois primeiros (a gênese e o desenho) uma vez que, nesse caso, não são as próprias instituições que estão em jogo, mas o que elas "fazem" (ou como elas "agem").

Claro está que arranjos institucionais não são nem meros reflexos de conflitos entre forças sociais, nem a causa dos conflitos sociais. Eles podem ser ou o objeto de disputa, ou o lugar da disputa, sendo freqüentemente, num regime ditatorial, ambos. De toda forma, nem um nem outro são indiferentes à dinâmica institucional, mas convém não tomar, na explicação, o efeito pela causa.

Configurações institucionais específicas não surgem simplesmente, se desenvolvem e se estabelecem para resolver determinados problemas postos pela clarividência dos seus criadores ou são impostas pelas exigências abstratas da "dinâmica social". Podem até fazê-lo, mas abordagens funcionalistas são, no máximo, uma hipótese entre outras para justificar a existência, decifrar o perfil e descrever o propósito de uma instituição, mesmo porque há toda sorte de efeitos não antecipados que a organização institucional pode produzir (Pierson e Skocpol, 2002). Sua influência, impacto ou ação - a "saliência institucional" na definição de A. Giddens (1974) - depende sempre dos contextos históricos e da dinâmica política.

\section{Conclusões}

A construção do problema teórico e a construção da resposta ao problema aproximaram, muito mais pelo assunto que pelo enfoque, minha explicação do neo-institucionalismo histórico. Pareceu-me mais efetivo abordar esses três temas - a mudança institucional, o desenho institucional e os efeitos institucionais dos dois primeiros - a partir de três proposições que se tornaram, curiosamente, propriedade dessa "teoria" à medida que foram 
explicitamente defendidas por ela: $i$ ) instituições são centrais na vida política, e isso deve ser entendido de duas maneiras: "teoricamente", instituições são uma variável explicativa (entre outras) dos processos políticos; "empiricamente", instituições não são apenas "caixas vazias" onde conflitos políticos ocorrem, mas são elas mesmas objeto de disputa política; ii) problemas políticos devem ser pensados por indução (a partir da História) e não por dedução (em função de teorias sociais muito gerais ou grandes modelos sociológicos); e iii) transformações de padrões institucionais devem sempre ser explicadas a partir de uma perspectiva multicausal e não por variáveis independentes (Steinmo, 2001).

Essa visão institucionalista foi forjada para contrapor-se a dois tipos de explicações. Uma que insistia no caráter personalista do regime e/ou do governo, onde a ordem política, exagerando, surgia como produto dos desígnios do Presidente imperial. Outra que ressaltava a modernização e a racionalização que o processo de remodelamento da administração pública (que teve como alfa e ômega a criação do DASP em 1938) teria imposto à máquina estatal. Afirmou-se a importância de uma ordem político-administrativa e o papel eminentemente político dos mecanismos institucionais do Estado Novo.

Deslocando o foco dessa problemática mais empírica (como estava organizado politicamente o regime; como funcionava burocraticamente o Estado etc.) para uma problemática mais histórica - quais foram as precondições para a concentração territorial do poder (Mann) e como esse processo concorria não apenas para a unificação dos subsistemas regionais, mas como ele repercutia na divisão do poder entre os grupos da oligarquia (no enquadramento dos "imperialismos estaduais", como se dizia) - é possível tematizar os vários ramos e repartições do Estado, o novo código administrativo, a personalização do poder de Estado, a burocratização das rotinas administrativas, a discriminação das facções da elite pelos níveis do governo etc. como um capítulo, o capítulo propriamente político, do processo de construção do Estado nacional no Brasil (State-building).

Essa problemática histórica deve ser formulada, contudo, dentro de ou a partir de uma problemática teórica diferente da usual - i.e., aquela que defende, para compreender esse período, as idéias de "Estado de compromisso" entre as frações da classe dominante e seu efeito (lógico e histórico), a "autonomia relativa" do Estado capitalista. O caso do Estado Novo 
ganha em interesse - e em capacidade explicativa - se pensado dentro da problemática weberiana da organização político-burocrática do Estado e da sua capacidade de exercer o poder sobre um determinado território, o que de resto Francisco Campos intuiu quando clamou pela necessidade e urgência de "articular o espaço" nacional e "impor o poder" presidencial.

A construção e o incremento da "capacidade estatal” (Skocpol) - seu papel enquanto ator e fator explicativo - passa justamente pelas reformas políticas implementadas pelo Estado Novo. Esse é uma forma de dizer que é o autoritarismo que irá portanto presidir os processos de construção institucional do (poder de) Estado no Brasil na primeira metade do século XX.

- Doutor em Ciência Política pela Universidade Estadual de Campinas (Unicamp), é Professor de Ciência Política na Universidade Federal de Paraná (UFPR); editor da Revista de Sociologia e Política (www.scielo.br/rsocp) e um dos coordenadores do Núcleo de Pesquisa em Sociologia Política Brasileira (NUSP) da UFPR.

${ }^{1}$ Lembro aqui os aparelhos propriamente ideológicos (o Departamento de Imprensa e Propaganda (DIP) e os vários Departamentos Estaduais de Imprensa e Propaganda, por exemplo); os aparelhos sociais e as instituições específicas destinadas a controlar/integrar as classes populares urbanas (o Ministério do Trabalho, a legislação social, o sindicato oficial); e as instituições econômicas (os conselhos governamentais de política industrial e comercial, de comércio exterior, de mobilização econômica etc.).

2 Julgo mais prudente, a fim de evitar a "personificação dos coletivos", precisar esse ponto: sempre onde se vê Estado e seus sucedâneos, leia-se 'os agentes estatais historicamente determinados'. Para a advertência, confira Bourdieu, Christin e Will, 2000, p. 3.

${ }^{3}$ Hall e Taylor chamam essa posição de "neo-institucionalismo sociológico" (2003).

${ }^{4}$ Uma aplicação bem anterior da idéia pode ser lida em Ferejohn e Fiorina, 1975.

5 Para uma atualização do argumento, veja Tilly e Goodin, 2006, p. 3-32.

${ }^{6}$ Sobre o caráter politicamente útil da evolução/transformação institucional, ver Rothstein, 1992, p. 57-89.

\section{Referências bibliográficas}

ARRAIS, M. 1938. O Estado Novo e suas diretrizes. Estudos políticos e constitucionais. Rio de Janeiro: José Olympio. 
BOURDIEU, P. CHRISTIN, O. e WILL, P.-É. 2000. Sur la science de l'État. Actes de la recherche em sciences sociales, vol. 133, n. 1.

BOURDIEU, P. 1996. Espíritos de Estado. Gênese e estrutura do campo burocrático. In: Razões práticas: sobre a teoria da ação. Campinas: Papirus.

CAMPOS, F. 1938. 10 de Novembro, resultado de 50 anos de experiência política. Rio de Janeiro: Departamento Nacional de Propaganda.

CAMPOS, F. 1940. O Estado nacional: sua estrutura; seu conteúdo ideológico. Rio de Janeiro: José Olympio.

CUNHA, M.W.V. da. 1963. O sistema administrativo brasileiro (19301950). Rio de Janeiro: Instituto Nacional de Estudos Pedagógicos.

DRAIBE, S. 1985. Rumos e metamorfoses: um estudo sobre a constituição do Estado e as alternativas da industrialização no Brasil, 1930/1960. Rio de Janeiro: Paz e Terra.

FEREJOHN, J. A. e FIORINA, M. P. 1975. Purposive Models of Legislative Behavior. American Economic Review. Papers and Proceedings of the Eighty-seventh Annual Meeting of the American Economic Association, vol. 65, n. 2, p. 407-414, May.

HALL, P. A. e TAYLOR, R. C. R. 2003. As três versões do neoinstitucionalismo. Lua Nova, n. 58.

HALL, P. 1986. Governing the Economy: The Politics of State Intervention in Britain and France. New York: Oxford University Press.

IKENBERRY, G. J. 1988. Conclusion: An Institutional Approach to American Foreign Economic Policy. International Organization, vol. 42, n. 1, p. 219-243, Winter.

IMMERGUT, E. M. 1998. The Theoretical Core of the New Institutionalism. Politics \& Society, vol. 26, n. 1, March.

KRASNER, S. D. 1984. Approaches to the State: Alternative Conceptions and Historical Dynamics. Comparative Politics, vol. 16, n. 2, p. 226-246, Jan.. 
MANN, M. 1992. O poder autônomo do Estado: suas origens, mecanismos e resultados. In: Hall, John A. (org.), Os Estados na História. Rio de Janeiro: Imago.

MARCH, J. e OLSEN, J. P. 1989. Rediscovering Institutions. The Organizational Basis of Politics. New York: Free Press.

MARCH, J. G. e OLSEN, J. P. 1984. The New Institutionalism: Organizational Factors in Political Life. American Political Science Review, vol. 78, n. 3, p. 734-749, Sep..

MARTINS, L. 1983. A revolução de 1930 e seu significado político. In: CPDOC/FGV, A revolução de 1930: seminário internacional. Brasília: Editora Universidade de Brasília.

MARTINS, L. 1976. Pouvoir et développement économique. Formation et évolution des structures politiques au Brésil. Paris: Anthropos.

NORDLINGER, E. A. 1988. The return to the state: Critiques. American Political Science Review, vol. 82, n. 3.

OFFE, C. 1975. The Theory of the Capitalist State and the Problem of Policy Formation. In: Lindberg, Leon N. et al. (eds.), Stress and Contradiction in Modern Capitalism. Lexington: Lexington Books.

OLIVEIRA, A. de S. 2002. O Exército nacional e o Estado Novo. In: Escritos políticos. São Paulo: Arx.

PETERS, B. G. 2003, El nuevo institucionalismo. La teoría institucional em ciencia política. Barcelona: Gedisa.

PIERSON, P. e SKOCPOL, T. 2002, Historical Institutionalism in Contemporary Political Science. In: Katznelson, Ira \& Milner, Helen V. (eds). Political Science: State of the Discipline. New York: W.W. Norton.

REIS, E. 1988. O Estado nacional como ideologia. Estudos Históricos, vol. 1, n. 1, p. 187-203.

ROTHSTEIN, B. 1992. Labor-market Institutions and Working-class Strength. In:Thelen, Katheleen; Steinmo, Sven e Longstreth, Frank 
(eds.), Structuring Politics: Historical Institutionalism in Comparative Analysis. Cambridge: Cambridge University Press.

SARTORI, G. 1994. Comparative Constitutional Engineering: An Inquiry into Structures, Incentives, and Outcomes. New York: New York University Press.

SHEPSLE, K. A. 1989. Studying Institutions. Some Lessons from the Rational Choice Approach. Journal of Theoretical Politics, vol. 1, n. 2, p. 131-149.

SKOCPOL, T. 1985. Bringing the State Back In: Strategies of Analysis in Current Research. In: Evans, Peter E.; Rueschemeyer, Dietrich; e (eds.), Bringing the State Back In. Cambridge: Cambridge

University Press.

STEINMO, S. 2001. The New Institutionalism. In: Clark, Paul Barry e Foweraker, Joe (eds.), The Encyclopedia of Democratic Thought. London: Routlege.

STEINMO, S.; THELEN, K. e LONGSTRETH, F. (eds.). 1992.

Structuring Politics: Historical Institutionalism in Comparative Analysis. Cambridge: Cambridge University Press.

THELEN, K. e STEINMO, S. 1992. Historical Institutionalism in Comparative Politics. In: Thelen, Katheleen e Steinmo, Sven e Longstreth, Frank (eds.), Structuring Politics: Historical Institutionalism in Comparative Analysis. Cambridge: Cambridge University Press.

THERBORN, G. 1978. What Does the Ruling Class Do When It Rules?: State Apparatuses and State Power under Feudalism, Capitalism and Socialism. London:Verso.

TILLY, C. e GOODIN, R. E. 2006. It Depends. In: Goodin, Robert E. e Tilly, Charles (eds.), The Oxford Handbook of Contextual Political Analysis. Oxford: Oxford University Press.

TILLY, C. 2004. Entrevista com Charles Tilly. Angela Alonso; Nadya Araujo Guimarães. Tempo Social, São Paulo, v. 16, n. 2, nov. 
VARGAS, G. 1995. Getúlio Vargas: diário. São Paulo: Siciliano; Rio de Janeiro: Fundação Getúlio Vargas.

VARGAS, G. 1938. Proclamação ao povo brasileiro (“À Nação”. Lida no Palácio Guanabara e irradiada para todo país na noite de 10 de novembro de 1937). In: . A nova política do Brasil. Rio de Janeiro: José Olympio.

VIANNA, O. 1974. Problemas de política objetiva. $3^{\mathrm{a}}$. ed. Rio de Janeiro: Record. 